\title{
Tritium Systems Test Assembly Quality Assurance Program
}

\author{
F. L. Kerstiens \\ R. C. Wilhelm
}

\section{DISCLAIMER}

\begin{abstract}
This report was prepared as an account of work sponsored by an agency of the United States Government. Neither the United States Government nor any agency thereof, nor any of their employees, makes any warranty, express or implied, or assumes any legal liability or responsibility for the accuracy, completeness, or usefulness of any information, apparatus, product, or process disclosed, or represents that its use would not infringe privately owned rights. Reference herein to any specific commercial product, process, or service by trade name, trademark, manufacturer, of otherwise does not necessarily constituie or imply its endorsement, recommendation. of favoring by the United States Government or any agercy thereof. The views and opinions of authors expressed herein do not necessarily state or reflect those of the United States Government or any agency thereor.
\end{abstract}




\title{
TRITIUM SYSTEMS TEST ASSEMBLY QUALITY ASSURANCE PROGRAM
}

hy

\author{
F. L. Kerstiens \\ K. C. Wilhelm
}

\begin{abstract}
A quality assurance program should establish the planned and systematic actions necessary to provide adequate confidence that fusion facilities and their subsystems will perform satisfactorily in service. The Tritium Systems Test Assembly (TSTA) Quality Assurance Program has been designed to assure that the designs, tests, data, and interpretive reports developed at TST A are ralid, accurate, and consistent with formally specified procedures and reviews. The quality consideration in all TSTA activities is directed toward the early detection of quality problems, coupled with timely and positive disposition and corrective action.
\end{abstract}

\section{INTRODUCTION}

The objective of the Tritium Systems Test Assembly (TSTA) is to develop and demonstrate an effective technology for handling and processing deuterium and tritium fuel for use in fusion reactors (Fig. 1). The TST.A program includes a major emphasis on the development of systems and procedures essential for ensuring and maintaining operating safety.

The principal goals of TSTA are to

- demonstrate and evaluate the fuel cycle for fusion power systems;

- develop and evaluate advanced safety systems for personnel and environmental protection;

- develop. test, and qualify equipment for tritium service in the fusion program:

- develop tritium-compatible components with long-term reliability:
- demonstrate long-term safe handling of tritium without hazardous incidents:

- investigate and evaluate the response of fuelhandling and environmental systems to normal and emergency situations;

- provide a reliable data base for tritium handling systems for future fusion facilities.

The supplementary goals of TSTA are to investigate and develop solutions for those problems that result from using radioactive tritium.

Although the Department of Energy (DOE) Oftice of Fusion Energy has not formally adopted a quality assurance standard for use at fusion tacilities, the quality assurance program at TSTA meets the requirements of ANSI/ASME NQA-1-1983 "Quality Assurance Requirements for Nuclear Facilities." NQA-1 sets forth the requirements for the establishment and execution of quality assurance programs during the design, construction, operation, and decommissioning of nuclear facilities. The DOE has selected NQA-I as the preferred standard in the nuclear area. 

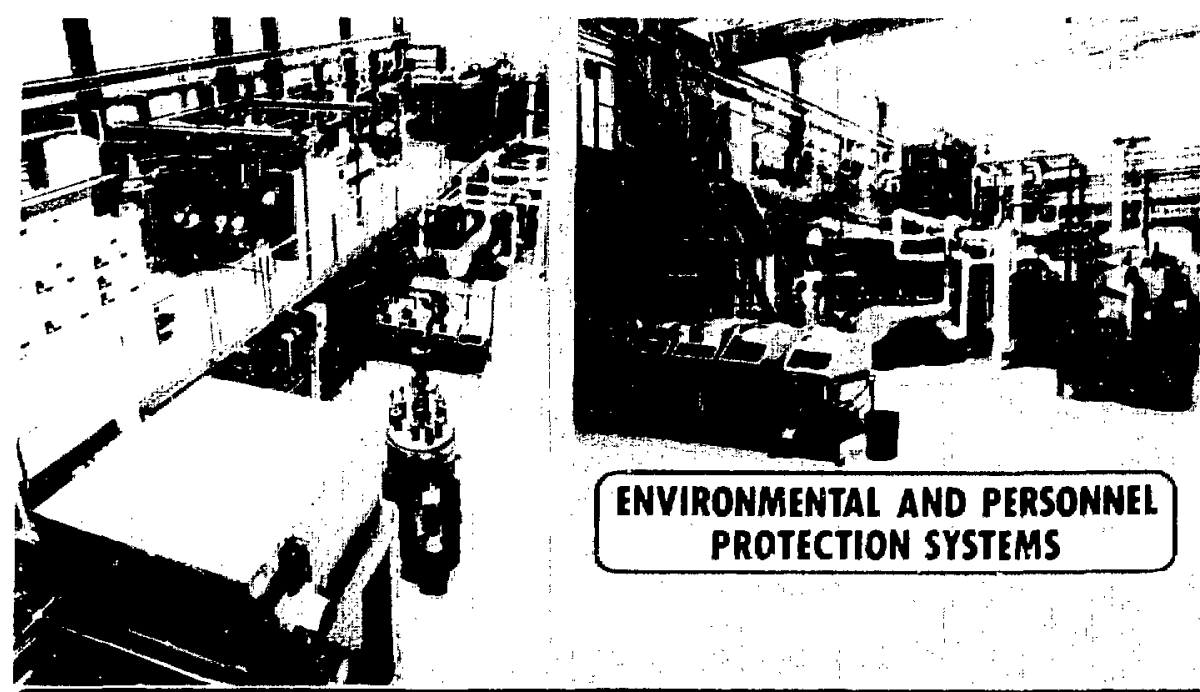

ENVIRONMENTAL AND PERSONNEL PROTECTION SYSTEMS
THE TRITIUM SYSTEMS TEST ASSEMBLY WILL DEVELOP AND EVALUATE TRITIUM TECHNOLOGY FOR THE MAGNETIC FUSION ENERGY PROGRAM
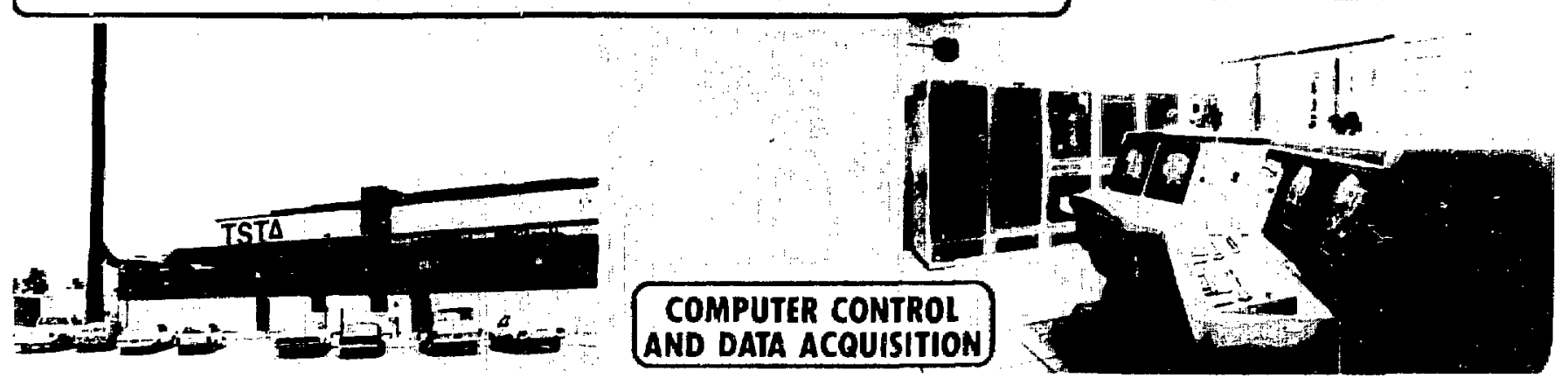

8

$=$

$\therefore 2$.

$=-$

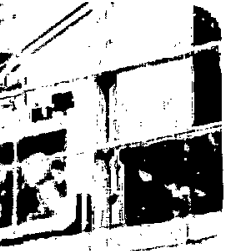

mine

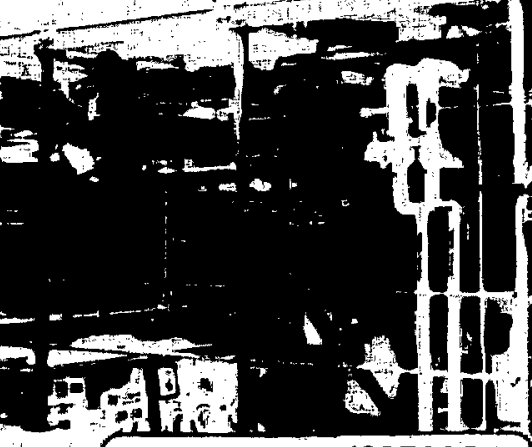

HYDROGEN ISOTOPE

SEPARATION SYSTEM CRYOGENIC DISTILIATION

Fig. 1. Overview photograph of TSTA showing the test cel] areas, building exterior, and control room 
The Materials Science and Technology (MST) Division Quality Assurance Manual, as implemented by Group MST-4. Engineering Design and Quality tssurance, is supplemented by the TST.t Quality tssurance Program Plan, and both are used to define requirements and specitications for TST A. Nationally recognized codes and standards, developed by the IEEE. ANSI, or ASME, have been used. as applicable, for the design and the operation of TST.A. When a recognized standard was not applicable in a particular situation but the need for a standard was obvious, a suitable project standard was formulated internally.

The TSTA Quality Assurance Program Plan sets forth the elements of a program for quality assurance and for methods of quality control and verification, which have heen used during the design. procurement. installation, operation, and milintenance platses of TSTA. The plan is designed to give broad guidance for ensuring that an appropriatte yuality assurance program is established, that quality objectives are met. and that activities affecting quality are correctly performed.

\section{ORGANIZATION AND QLALITY ASSURANCE. PROGRAM}

TST.t quality assurance personnel are responsible for assuring that activities affecting quality have been accomplished in accordance with prescribed plans. Therefore, they have been given sufficient authority, access to work areas, and organizational freedom to identify quality problems: to initiate, recommend. or piuvide solutions to quality problems: and to verify the implementation of solutions.

In order to meet these responsibilities. quality assurance personnel perform a variety of duties:

- identify. develop. approve, implement, and maintain quality assurance procedures:

- assist TSTA technical personnel in the selection of quality assurance requirements:

- review all technical procedures. instructions, and policies that make up the quality assurance program to help assure compliance with quality requirements:

- establish requirements for quality assurance training and indoctrination:

- determine the need for and scope of quality assurance audits and inspections;
- approve the disposition of TSTA nonconformances and corrective actions.

TSTA technical management provides organizational support for assuring that quality assurance requirements are complied with in all aspects of research and in the resulting documentation phases. Technical and quality assurance managenent regularly assess the adequacy of the quality assurance program and modify the program as necessary to meet expanding requirements.

Review boards are used extensively throughout TST A for acceptance of project documents, for review and acceptance of designs and design changes. for review and acceptance of material and product nonconformanees, atal for final product acceptance. A review board consists of a menber of TST A technical nanagement, a representative from the TST $A$ quality assurance staff. and at least one lechnical reviewer who has the technical ability to perform the review but has no direct responsibility for the item or work under review. The review board has the responsibility and the authority to determine the adequacy of TSTA desigris. validity of the analytical approach, conformance of designs to all design requirements. and completeness of documentation.

\section{DESIGN CONTROL.}

All materials, subassemblies, systems, and operations where design or operational adequacy is to be established are verified by design reviews. Design reviews help maintain and improve the overall quality of engineering design and documentation effort by ensuring

- use of the best available data. technical expertise, and analytical methods:

- proper coordination of engineering designs:

- adequate and consistent design study and documentation of engineering design activity;

- complete documentation of design choice and substantiating data.

Alternate calculations and testing programs are used as needed to verify designs. All personnel performing TSTA design verification have demonstrated the knowledge, experience, and trainir.s to adequately perform design reviews but do not have a direct responsibility for the original design. 
Project documents and drawings are not considered released until they have been aceepted by a documented review board and have been approved by TST t management and Quality Assurance. Revisions and changes to TSTA documents and drawings require the same level of review and approval as do the originals.

TST.A Quality Assurance prepares monthly reports defining the status of design reviews and design changes. TSTA subsystem designers are informed as 10 which design reviews and design changes are still oper. and not approved or completed. TST t technical management also receives a generalized report that lists all open and uncompleted design reviews and design changes for all facility subsystems. This report helps ensure that all TST $t$ design and managenent personnel are aware of the status of TST 1 subsystem upgrades and tacilit? atailability

\section{DOCUNENT.ATION}

Quality assurance procedures have been premred for major portions of the Quality Assurance Program Plan to delineate specific quality assurance requirements and the methods to accomplish these reciuirements. These procedures cover subjects such as document and records control, nonconformance and corrective action reporting. operator training. component and equipment failure reporting, procurement, and calibration. Additional quality assurance procedures are prepared as the TST A program progresses.

System design descriptions (SDD) are prepared for each major TSTA subsystem and include design requirements; design features such as flow paths and subsystem performance: subsystem arrangement; subsystem operating and design parameters; component design features: anticipated conditions of subsystem maintenance and operation: level of quality assurance: reliability-critical items; and any codes and standards to be applied to the subsystem design, construction. testing. and operation. The SDD ultimately serves as the basis for the preparation of Component Specifications, Operating Procedures, Preventive and Corrective Maintenance Procedures, Calibration Procedures, Detailed Test Procedures, Emcrgent'y. Procedures, and detailed subsystern drawings.

Specification documents are prepared for subsystem components that are required to meet established design and manufacturer requirements. Specifications discuss the applicable codes and standards; any design requirements including special materials, performance data, leak rates, and maintenance; quality asstirance requirements including test results. certificates of conformance and calibration, and documentation to be supplied to TST. and methods w packaging and shipping.

ts TST t becomes anore operational, operating procedures will provide instructions on operating individual components as well as on operating complex subsystems. Operating procedures provide information to personnel that includes interfacing subsystems or special equipment required: prerecpuisites to be met before performing the operation; data to be recorded during the operation: references that can be used, such as technical nalluals or drawings; and the step-by-step instructions governing the operation.

Because much of the TST t fucility is contaminated with tritium, instrument calibrations must be performed in y/tu. To help ensure that calibrations are valid. reproducible, and documented, callibration procedures are written to describe the calibration process. Calibrition procidures include a list of equipment necessart wo perform the calibration; prerequesites to be met before the calibration: the required accuracy and precision eriteria; the acceptance/rejection criteria; documentation to be prepared to support the calibration: references, including technical manuals, drawings, or other approved procedures; and the detailed step-bystep instructions describing the calibration.

TSTA Quality Assurance maintains the measuring and test equipment data base. When calibrations are satisfactorily completed and the item is placed back in service, either in-line or on the shelf. the appropriate subsystem designer fills out a quality assurance calibration card. files the calibration data, and affixes a calibration sticker to the piece of equipment. The catibration card is given to the TSTA quality assurance staff for filing and contains the necessary information for the calibration data base. The calibration sticker is used to identify the piece of equipment as being part of a quality assurance program and ieminds the operators of their responsibility to verify calibration of the equipment before its use.

Emergency procedures will be prepared as operational experience is gained. The emergency procedures describe what indications are available for the identification of an emergency situation; the step-by-step immediate actions to be taken to place the subsystem or facility into a safe condition; the step-by-step supplementary actions to be taken to recover the subsystem or facility: and references. which could include other procedures, drawings, or technical manuals.

Complete volumes of procedures (Fig. 2) for each major TSTA subsystem are maintained in the TSTA control room and support center. These ensure ready reference to all subsystem and facility documentation for routine TSTA operations, planned off-normal operations, and support of operator training. A complete set of manuals is also kept in the TSTA quality 


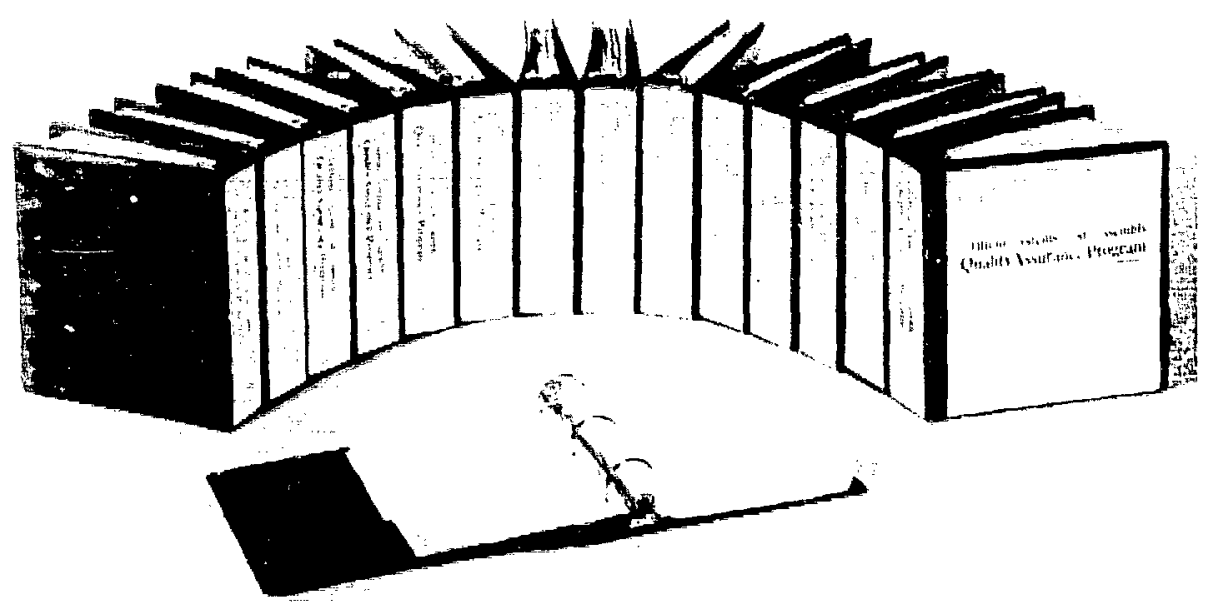

Fig. 2. TST 1 quality assurance procedures manuals.

assurance office and by the TSTA project manager. Subsystem designers have been issued a partial set of manuals that are pertinent to their subsystems. These include the manuals of quality assurance procedures, generic procedures, and their subsystem procedures.

Technical and quality assurance procedures are prepared by TSTA technical and quality assurance personnel respectively and are maintained on word processor diskettes. All original, approved tocuments are filed and stored by quality assurance. If a copy of a procedure is needed. it can be quickly recovered and copied. Quality Assurance also maintains the document historical file that allows TSTA and DOE personnel to review project documentation from the original through the revision currently in use.

Procedures indexes are maintained by Quality Assurance in the form of tables of contents for each procedures manual. The table of contents is divided into sections corresponding to the different types of documents in the manual and lists earh document by unique identifier, current revision, title of the procedure, and the date the procedure was approved for use.

Quality Assurance maintains three complete sets of TSTA drawings. Two sets are working sets and one set is the master file. A working set is maintained in the main test cell area and is used by TSTA personnel as needed for reference. Project personnel are encouraged to note any discrepancies between the drawing and the "asbuilt" equipment on these drawings by sketching in the change by hand with red ink and initialing and dating the modification. Quality assurance personnel routinely review drawings for changes and arrange for a formal revision of the drawings. The other working set of drawings is kept in the TSTA quality assurance office for use by all personnel outside the TSTA test cell area.

Drawing indexes are maintained by Quality Assurance for each set of TSTA drawings. Each index is divided by facility subsystem and lists each drawing by identifier, current revision (page by page), drawing title, and alternate drawing numbers in use for that drawing.

\section{OPERATOR TRAINING}

Facility operators control and monitor TSTA during normal, emergency, and maintenance phases. Their performance is critical both for operational safety, assuring no release of tritium to the atmospherc, and to the successful simulation of the fusion reaction process. The detailed knowledge and experience required of operators for the operation and maintenance of TSTA are obtained through individual study, scheduled training sessions, and on-the-job training for the operator.

Formal operator training at TSTA is helping to ensure that operators have the knowledge not only to properly operate TSTA during steady-state and transient conditions but also to be capable of recognizing an unsafe condition and to take proper actions either to correct the problem or to place the subsystems and facility into a stable and safe condition.

The basic guideline for training is that the operators know not only what actions to take but also the reasons for taking the appropriate action and the effect that action will have on each subsystem and on the facility as a whole. This detailed knowledge can only be gained through a formal and structured training program that 
ensures that operators know what their responsibilities and duties are and what knowledge is necessary to carry out those duties and responsibilities.

\section{A. TST A Training Sessions}

Training sessions are periodically scheduled tor all TSTA personnel to provide basic knowl.tige or and familiarity with individual subsystems, TST.t as an integrated facility, and all scheduled experiments and tests. These sessions are given by personnel knowledgeable in the operation of the TSTA facility and its subsystems, Instructors may include subsystem designers, qualified operators, or safety personnel from other areas of Los Alamos National Laboratory.

All subsystem training sessions are designed to give TSTA persennel a basic introd." cion to individual subsystems. CSTA operators are expected to gain more in-depth knowledge of subsystems by using the TSTA procedures marnals, instrument and component technical manuals, and subsystem and facility drawings (Fig. 3).

As TSTA operation is expanded and functional subsystems are integrated into a total operating facility, the training sessions will be expanded to allow operators to maintain adequate levels of knowledge to safely operate TSTA. Emphasis will be on potential accident situations with attention given to

- methods to quickly detect and recognize abnormal conditions by using existing instrumentation;

- discussion of the most stable conditions for the subsystem or facility and methods to place the subsystem or facility into that condition:
- operator actions and subsystem and facility conditions to avoid;

- discussion of potential consequences if the abnormal situation deteriorates and of the immediate actions required to obtain additional assistance, to minimize hazards to TSTA personnel and equipment, and to prevent the situation from worsening.

\section{B. Qualification Checklists}

The basic training and qualification guide is the qualification checklist (Fig. 4). Checklists have been prepared for each TSTA subsystem and serve both as training guides for the operator by identifying the minimum items that must be completed and as a method for the qualifier, who is normally the subsystem designer or someone designated by TSTA management, to denote satisfactory completion of the specific items. All checklists are periodically reviewed to ensure their effectiveness, completeness, and accuracy as training guides. Operators and subsystem designers are responsible for keeping the checklists current with TSTA technoiogy.

Qualification checklists address major areas of knowledge required by an operator to operate and monitor TSTA in a safe and efficient manner. All certified TSTA operators must be knowledgeable in the following areas:

- TSTA subsystems and subsystem components

- subsystem operation

- subsystem and facility operating principles

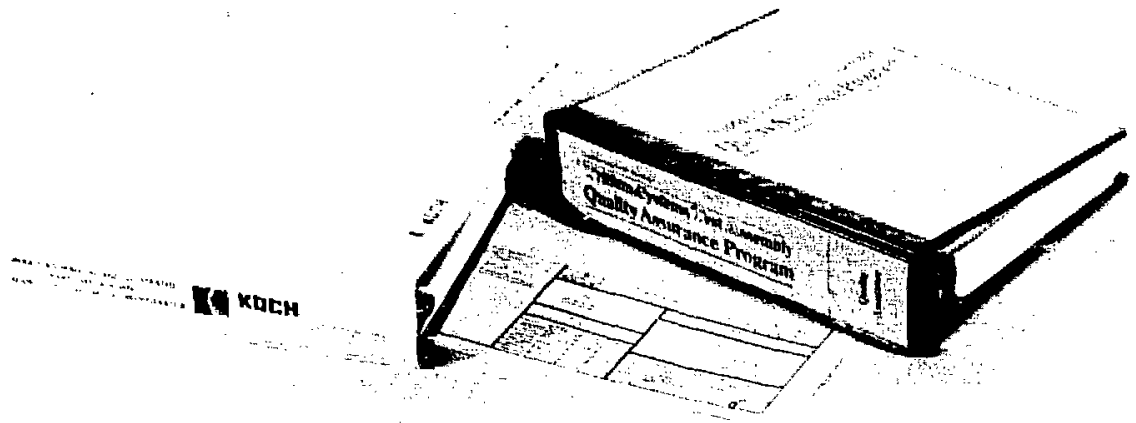

Fig. 3. TSTA training aids. 


\section{Iritium Systems Test Assembly \\ Facility Operator I}

\section{Operator Name}

20. Uninterruptable Power Supply (UPS)

(Prerequisites - Safety Cards, Physical Plant and Utilities, Basic TSTA Operation)

\section{Subsystem Knowledge}

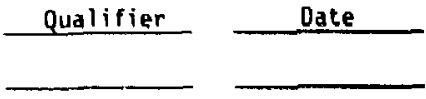

1) Block Flow Diagran (Electrical)

2) Components

Battery Disconnect 5 witch

Storage batteries

OC rectifier

$A C$ invertar

Transfer switch

Bypass Transformer

3) Operating modes

4) Operating limits

5) MDAC

HMl display information

$$
\text { Alarm messages }
$$

6) Normal operations

7) Emergency procedures

8) Subsystem interfaces

9) Special hazards (Chemical, $\mathrm{H}_{2}$ )

\section{Subsystem Practical Factors}

1) Startup and Shut Down UPS (Simulate)

2) Place UPS in bypass mode

3) Place UPS in normal mode

4) Place UF 5 in downgraded mode

5) Response to failure or abnormal conditions

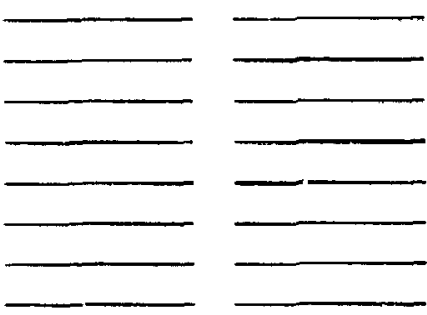

\section{Subsystem Safety Knowledge}
1) Electrical safety
2) Mechanical safety

Final Approval

Fig. 4. Typical TSTA qualification checklist. 
- normal and emergency operating procedures

- administrative procedures

- health and safety considerations

Operators demonstrate satisfactory knowledge of these areas through oral checkouts, written examinations, and the completion of practical hands-on exercises.

\section{Oral Checkout}

The oral checkout is intended to be a means of assessing an operator's level of knowledge on each subsystem. Operators are expected to demonsirale a minimum level of knowledge of the subsystem including

- subsystem construction and function within TSTA and the theory of subsystem operation;

- ability to draw a basic subsystem line diagram with major components;

- subsystem operating modes, normal operating parameters, and control stations:

- subsystem interlocks, automatic and manual features. and operating limitations;

- results of subsystem or component failures and what actions to take:

- basic structure of the subsystem software control program, commands allowed from the man/machine interface, and the meaning of display messages.

When the operator feels confident of having mastered the required material, the qualifier giving the checkout will have a discussion with the operator. Using the qualification checklist as a guide, the qualifier asks the operator questions on the subsystem. If the operator demonstrates an adequate level of knowledge of the subsystem, the qualifier who gave the checkout will sign and date the appropriate items on the checklist. If, during the oral checkout. the operator does not demonstrate a sufficient level of knowledge of a particular subject, the qualifier can require additional study and completion of that portion of the checklist at a later date.
The oral checkout is expected to take a mininum amount of time, but the actual time required will depend on subsystem complexity, anticipated operations, and whether the checkout is for initial qualification or requalification.

\section{Practical Factors}

Practical factors are the hands-on operations required of an operator. These are completed under the direct supervision of the subsystem designer or someone designated by TSTA management.

To satisfactorily complete the practical factors section of the qualification checklist, operators must demonstrate a detailed working knowledge of subsystem and component prestart requirements, startup and shutdown operations, normal and emergency operations, and preventive maintenance.

A detailed discussion between operator and qualifier is held before the operator actually performs the operation. This includes

- the prcredure to be used and the effect the performance of the procedure will have on the subsystem and interfacing subsystems;

- precautions to be taken and subsystem or component limitations to be cognizant of:

- equipment to be monitored and normal operating conditions to be expected:

- response to any anticipated abnormal conditions;

- documentation required during operations.

Practical factors are completed any time the handson operation can be performed, during subsystem and facility startups and shutdowns, testing, maintenance phases, or normal operations. Every effort is made to perform the practical factors. However, if it is not possible to schedule a required operation before qualification, the practical factor can be simulated by a walkthrough of the procedure as if it werc actually performed, except that valves and switches are not manipulated.

If the operator demonstrates an adequate level of knowledge, the qualifier will sign and date the appropriate section of the qualification checklist. If any practical factor is simulated, it is noted on the checklist and the operator may be required to actually perform the task at a later date. 


\section{E. Written Examinations}

Written examinations will be used to test the knowtedge level of operators and to measure each operator's qualification. progress. Examinations will be given alt various stages of training as determined by the operator's qualification progress or anticipated operations and may include both written and practical sessions.

titer training and all qualification checklists have been completed. al comprehensive tinal examination will be given. All safety-related questions must be answered 100\% correctly, or the examination must be retaken after a period of restudy.

As more operators are trained to operate TST.A, a data bank of test questions will be compiled, and tests will beconte sisier to assemble and will become more standardicid.

\section{F. Requalification/Recertification}

Qualified operators must successfully complete specific requirements att regular intervals to retain certification. Operators must attend all training lectures scheduled by TST $t$ management and may be designated to present a training lecture. Qualified operators must successtully complete a yearly comprehensive exarnination that covers normal and emergency operations and subsystem and facility knowledge. Every two years, qualified operators will also be reyuired to complete the entire training program again. Operators requalifying will need to demonstrate more comprehensive knowledge and levels of understanding than were required for the initial qualitication. Special imphasis will be given to subsystem modifications and problems encountered since the last date of qualification.

\section{SUBSYSTEMI AND F ACILITY TESTING}

TST. subsystems are being integrated into an operational facility in a very controlled and safe manner. One method used to help assure this controlled, safe startup is the preparation and use of test plans before the start of all TSTA experiments and tests. Test plan preparation allows the test coordinator to evaluate all variables involved before aetual testing.

All test plans outline the subsystem or facility conliguration required for the test. other subsystems required to interface with the subsystem being tested. possible hazards associated with the test, personnel requirements. a brief and concise description of the test. and a description of what data are to be taken and how the data will be recorded. This document is submitted to a review board and, if approved. is distributed to all project personnel before testing. This allows ample tinue for a final, in formal review of the entire project.

If the review board or TSTA management feels the test plan is not adequate or needs more detail, a detailed test procedure is prepared. This document describes the test in more detail including a step-by-step description of the anticipated operations. Instructions are included on how to calibrate and operate equipment used in the test, and the acceptance/rejection criteria are stated.

Because TST $t$ is designed to be computer controlled, all software is subject to the same testing requirements as is hardware. Software documentation includes a test plan with test results, a structured chart describing the software, a written deseription in English, and a detailed operating procedure describing how to use the software. Once software has been accepted for use, it is treated as any other TSTA docunient and carnot be revised or modified without undergoing a documented design change. This helps ensure that only authorized software is in use to operate TST.A.

At the completion of each test, test results are prepared that address the major areas of testing as related to the test plan or detailed test procedure. Test results are distributed to all TSTA personnel to keep them knowledgeable of TSTA activitics and schedule conımitments. In addition, test results become an appendix to the original test plan or detailed test procedure and are distributed to all TSTA quality assurance procedures manuals for needed reference. TSTA Quality Assurance submits monthly reports to TSTA subsystem designers and TSTA technical management outlining the status of tests and the preparation of test results.

\section{NONCONFORMANCE AND CORRECTIVE ACTION REPORTING}

TSTA has established a two-level system for reporting problems. The first level consists of TST A personnel completing a TSTA failure and corrective maintenance report for each component, piece of equipment, or control software that fails to function properly or needs major adjustment to continue operation. These forms are located throughout the facility, and TSTA Quality Assurance routinely collects completed forms for entry into a data base used for reliability studies and maintenance record keeping.

The report form is a two-part, two-page sct of forms designed to diagnose a problem and furnish enough information to have the problem corrected by the appropriate personnel. The form furnishes enough data to be compatible in format with the Centralized Reliability Data Organization (CREDO) data base. CREDO is an organization whose purpose is to define, develop, and 
maintain a national center for the collection, evaluation, analysis, and dissemination of advanced reactor reliability, availability, and maintainability data in support of advanced reactor safety, reliability, and licensing.

Members of the fusion community and CREDO personnel determined that the CREDO data base would be an excellent means, if adapted properly, to track fusion reactor reliability, availability, and maintainability data. TSTA, being the only fusion engineering tacility to keep track ol component failure data in a systematic way since its inception, was chosen to institute a CREDO-compatible data-gathering effort.

One of the first and most complex portions of the task was to compile a list of components belonging to one major subsystem of TSTA. Only one subsystem was chosen because of the complexity of attempting to index every component of TSTA. The Tritium Waste Treatment (TWT) subsystem was selected because it has been the subsystem longest in continuous operation at TST A. Over 200 separate components were identified and assigned a CREDO I.D. number. This number refers to what is termed CREDO engineering data, one of two types of data collected by CREDO. Engineering data are unique. detailed descriptions of components in terms of engineering parameters that are collected for all of the separate components in the TWT subsystem.

The next data type is CREDO event data, which are unique, detailed descriptions of circumstances before. during, and after a component failure. This information is reported on the TSTA reporting forms (Fig. S) and includes

- Subsystem-the paricicular subsystem at TSTA involved in the failure;

- Originator-the person initiating the report:

- Date-the date the report is initiated;

- TSTA Parameter Number-the particular TSTA parameter reading or the name of the component being examined when the failure occurred;

- Subsystem Parameters at Time of Failure-any displays or readings that might be helpful in determining what was happening at the time of the failure:

- Subsystem Configuration at Time of Failure-the operating status of the subsystem when the failure occutred:

- Failure Narrative-a descriptive account of the failure, including symptoms and cause, if known;
- Effect on TSTA Operations-a specific account of the effects of the failure on the subsystem and entire facility and the time lost cut to the failure.

TST A quality assurance personnel enter these data into the data base, assign them report numbers, and forward the report to the appropriate subsystem designer who determines who will perform the corrective maintenance. Based on the information given by the origimator of the report. repair personnel troubleshoot and correct the failure. The: then complete the remainder of the report, which includec

- Failed Component-the specific component involved in the failure;

- Serial Number and Model Number;

- Problem with Component-the reason for failure (sofiware, electrical or mechanical problems, etc.):

- Specific Problem Description-a concise description of the cause of the failure, including any unusual circumstances;

- Cause-the cause of the failure (software, personnol, material, design, procedures, etc.);

- Description of Corrective Maintenance Taken to Correct the Failure-a brief description of what was done to the failed component to bring it back to its prefailure condition;

- Special Maintenance Equipment Required-a list of any special tools or equipment needed to repair or replace the failed component;

- Time Required for Component Repair or Replacement-an cstimate of the time it took to repair or replace the failed component;

- Unusual Circumstances Causing Long or Short Repair/Replacement Time-a checklist of $i, \mathrm{ems}$ to be identified if they were the cause of excessively long or short repair/replace times (accessibility, size and weight of component, connections, contamination, etc. ):

- ivethod Used for Verification of System Operational Status - a description of the method used to assure that the component will operate properly before restarting the entire subsystem or facility. 


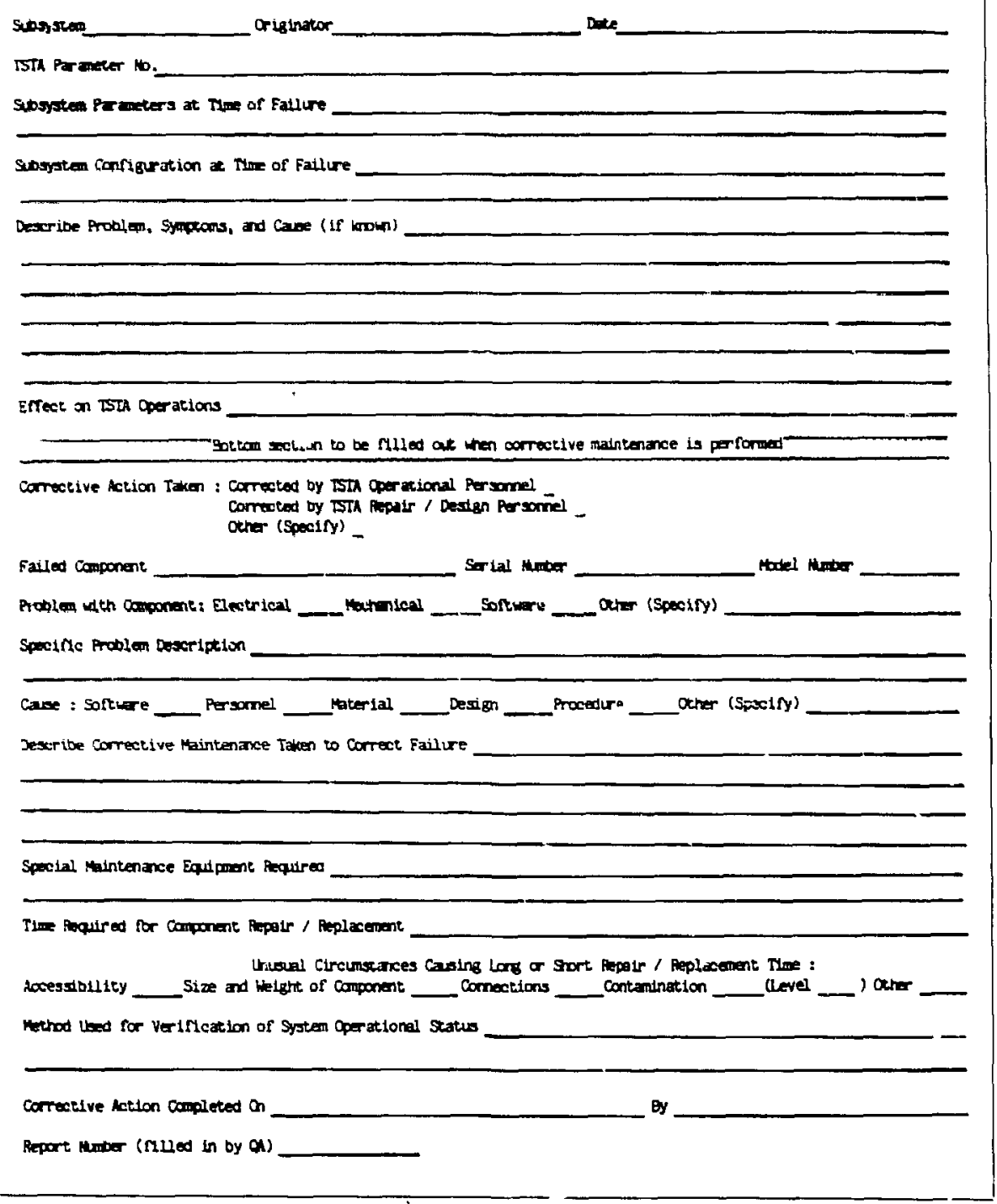

Fig. 5. TSTA failure and corrective maintenance repor.

Repair personnel sign and date the report and return it to TSTA quality assurance personncl who enter the repair data into the data base. If the originator also performed the corrective maintenance, he completes the entire form and submits it to Quality Assurance.

All failure data can be taken off the TSTA report forms. converted to the CREDO event data reporting form. and sent to CREDO for inclusion in its data base. where the data can then be accessed by any organization needing reliability, availability, and maintainability data for the fusion community.
TSTA Quality Assurance submits monthly, to each subsystem designer, the status of failures associated with the designer's subsystem. This report lists what failures have occurred since the last reporting date, what failures are still open and require corrective maintenance, and what failure reports were closed out with corrective maintenance performed. TSTA technical management gets a generalized report describing overall TSTA failures on each subsystem (including which are open and which are closed out) and giving a brief description of the failures. 
As TSTA becomes more operational and more failure data are recorded, quality assurance personnel will correlate data for reliability/availability studies. The information recorded thus far is being used to determine preventive maintenance intervals and to write preventive and corrective maintenance procedures, operating procedures, emergency procedures, and procurement requirements.

If the problem is significant, recurrent, or resulted from a design deficiency, a nonconformance report (NCR) is issued, which is the second level of problem reporting. NCRs are controlled at the quality assurance management and TSTA project management level and include the problem and cause along with the disposition required to correct the problem. Dispositions are classified in four categories:

- Use-as-is-acceptance of a nonconforming item for use without restrictions;

- Reject-the nonconforming item is unacceptable for use and is segregated;

- Rework-a nonconforming item is made to conform to original drawings or specifications;

- Repair-a nonconforming item is restored to a functional condition but is not necessarily in compliance with the original specification.

If deemed necessary by Quality Assurance and TSTA technical management, a corrective action report is completed. This outlines the method of preventing a nonconforming condition from recurring. This may include procedural revisions or additional personnel training requirements. Quality assurarice surveillance then assures that all proposed dispositions and corrective actions are completed in a timely manner.

\section{AUDITING}

Qualitv assurance audits are periodically performed on the TSTA project to provide an adequate assessment of the effectiveness of procedures, inspections, tests, process controls, and documentation practices.
Audits are scheduled every 12 to 18 months depending on TSTA quality history and complexity of operations.

Audit teams are randomly selected from qualified Los Alamos quality assurance personnel who have no direst responsibilities at TSTA. This ensures a completely independent evaluation of the TSTA quality assurance program.

Audit deficiencies are classified into two categories (FiE, 6):

- Audit Finding-a significant noncompliance to a specified quality requirement that is considered by the audit team to be worthy of corractive action. $A$ written response by TSTA management is required describing corrective action.

- Audit Observation-a condition that is considered to be of less significance than a finding but is reported to TSTA management for information. A formal response is not required.

Audit reports are prepared by the audit team and address the purpose and scope of the audit; checklists used; auditors, with the lead auditor identified; personnel contacted and their organization; summary of the audit; and the audit finding and audit observation reports, numbered and ordered in order of significance, as attachments. Quality Assurance reviews the audit results with TSTA technical management, which determines the action necessary to correct the situation. TSTA quality assurance personnel work with TSTA technical management to determine the proper corrective action and to help implement it.

The Los Alamos quality assurance organization performs audit trending to determine recurring problem areas, to verify overall quality program implementation, and to schedule audits and reaudits.

\section{SUMMARY}

The TSTA Quality Assurance Program Plan has furnished TSTA with the methods for assuring that all significant actions are planned and systematic. Having procedures for all tests and operations enables TSTA to 


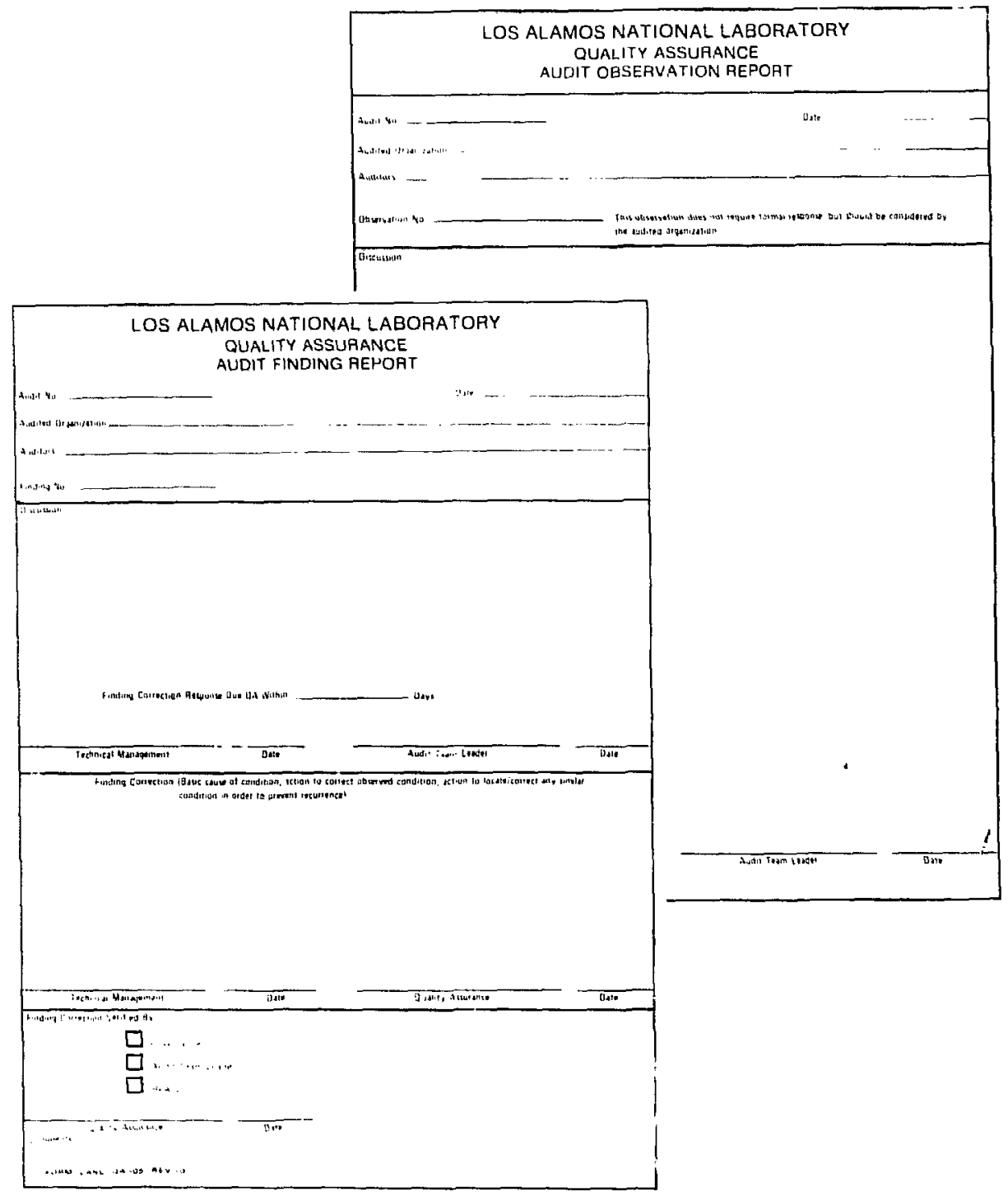

Fig. 6. Audit finding and audit observation reports.

provide planned control over actions and provide repeatability of all research efforts. Design reviews have provided for the interchange of ideas between subsystem designers, facility operators, and TSTA technical and quality assurance management. Reviews also have furnished documented evidence of personnel involvement in the design, construction, and operation of TSTA.

Quality Assurance has provided the methods for identifying and reporting facility and subsystem prob- lems and for trending these problems to prevent recurrence.

TSTA researchers must prepare documentation to record their activities. Although this process requires valuable time, it facilitates better understanding of the functioning of both individual subsystems and of TSTA as a whole. This documentation also serves as a means of recording TSTA research activities for future fusion projects and as a method of evaluating TSTA progress for effectiveness. 